\title{
A Case Study of Geometric Modelling via 3-D Point Interpolation for the Bathymetry of the Rabasa Lakes (Alicante, Spain)
}

\author{
África de la Hera ${ }^{1}$, Enrique López-Pamo ${ }^{1}$, Esther Santofimia ${ }^{1}$, Guillermo Gallego ${ }^{2}$, \\ Raquel Morales ${ }^{1}$, Juan José Durán-Valsero ${ }^{1}$ and José Manuel Murillo-Díaz ${ }^{1}$ \\ ${ }^{1}$ Geological Survey of Spain, C/ Ríos Rosas, 23, 28003 Madrid, Spain \\ a.delahera@igme.es, e.lopez@igme.es, e.santofimia@igme.es, r.morales@igme.es, \\ jj.duran@igme.es,jm.murillo@igme.es \\ ${ }^{2}$ Universidad Politécnica de Madrid, Avda. Complutense 30, 28040 Madrid, Spain \\ ggb@gti.ssr.upm.es
}

\begin{abstract}
The interpolation of points by means of Information Technology programs appears as a technical tool of some relevancy in the hydrogeology in general and in the study of the humid zones in particular. Our approach has been the determination of the 3-D geometry of the humid zones of major depth of the Rabasa Lakes. To estimate the topography of the lake bed, we proceed to acquire information in the field by means of sonar and GPS equipment. A total of 335 points were measured both on the perimeter and in the lake bed. In a second stage, this information was used in a kriging program to obtain the bathymetry of the wetland. This methodology is demonstrated as one of the most reliable and cost-efficient for the 3-D analysis of this type of water masses. The bathymetric study of the zone allows us to characterize the mid- and long-term hydrological evolution of the lakes by means of depth-area-volume curves.
\end{abstract}

Keywords: Bathymetry, Kriging, Lake, Rabasa, Sonar.

\section{Introduction}

In a partnership between the Geological Survey of Spain and the Regional Government of Alicante, a study of the wetlands in the province is being carried out. The Rabasa Lakes, located North-East from the city of Alicante, have been formed as a consequence of the rising of the groundwater level in a quarry (Fig. 1) that was aban- 
doned in the 1970s. There are three lakes of size 0.5, 1.5 and 3 ha. The largest lake has been selected to carry out a bathymetric study.

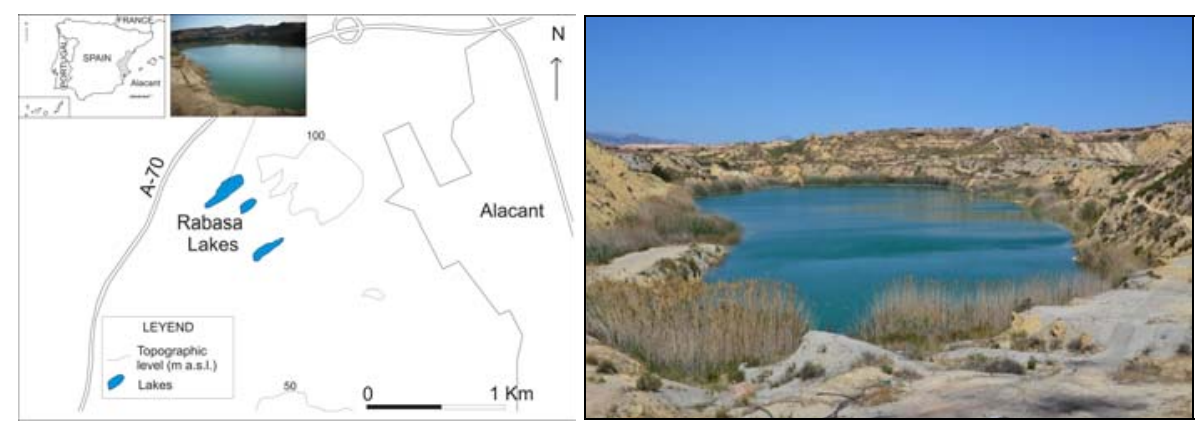

Fig. 1. Location and view of the Rabasa Lakes in the province of Alicante, Spain.

The methods to obtain bathymetric maps of rivers, lakes, ocean floors, etc. are diverse. Acoustic, visual and computer technology, as well as Global Positioning Systems (GPS) are at the foundations of modern bathymetry systems. Single beam echo sounders (SBES), on ships infer the topography of the sea floor by emitting an acoustic pulse and measuring the travel time it takes the wave to return to the ship after being reflected by the sea floor. Multibeam echo sounders [1] (MBES) provide higher accuracy and angular resolution by correcting for the movements of the ship. Bathymetry in shallow waters (depth $<50 \mathrm{~m}$ ) can be measured from aircrafts by means of airborne laser radar (LIDAR) [2]. Such systems infer the water depth by sensing the echo of emitted laser light pulses that are reflected by the water surface and the water bottom. Optical bathymetry methods are usually cost effective and efficient over large areas of clean water bodies.

\section{Methodology}

In this work, a bathymetry technique based on acoustic technology is presented. The estimation of the topography of the Rabasa lake bed consists of two stages. First, in situ measurements are obtained by means of sonar and GPS equipment. A Garmin 160C Fishfinder sonar probe and a Garmin 76S GPS receiver working in differential mode were used to collect a total of 335 points measurements spatially distributed throughout the lake. In a second stage, the data is processed by scientific software [3] that, by means of the method of ordinary kriging, returns and estimate of the wetland bathymetry.

Kriging $[4,5]$ is widely used in hydrogeology as the preferred method for constructing datasets, usually over unstructured 2-D grids, suitable for contouring. It is a method closely related to the best linear unbiased estimation (BLUE) in Statistics. Given the observed depths $\mathrm{Z}\left(\mathrm{x}_{\mathrm{i}}\right)$ at locations $\mathrm{x}_{\mathrm{i}} \in \mathrm{R}^{2}, i=1, \ldots, N$, the kriging method interpolates the depth at an unobserved location $\mathrm{x}_{0}$ using a linear combination of the 
known depths: $\check{Z}\left(\mathrm{x}_{0}\right)=\sum_{\mathrm{i}=1}^{\mathrm{N}} \mathrm{w}_{\mathrm{i}}\left(\mathrm{x}_{0}\right) \mathrm{Z}\left(\mathrm{x}_{\mathrm{i}}\right)$. The weights $\mathrm{w}_{\mathrm{i}}\left(\mathrm{x}_{0}\right)$ depend on the distance from $x_{0}$ to the known locations $x_{i}$, i.e., $\left\|x_{0}-x_{i}\right\|$, and are calculated based on hypothesis of the ordinary kriging method.

\section{Results}

The geometric modelling of a lake basin by means of an interpolated surface through a set of scattered 3-D points allows us to analyze the lake bed as a whole. For the largest Rabasa Lakes 335 points were measured, out of which 217 belong to the flooded area. Fig. 2a shows the location of the collected field points. The minimum, median and maximum water depths are $0,8.4$ and $18 \mathrm{~m}$, respectively. The mean water depth and the standard deviation are $8.49 \mathrm{~m}$ and $5.33 \mathrm{~m}$, respectively. The average distance between nearest neighbor points is $5.93 \mathrm{~m}$. The corresponding topographic map estimated using ordinary kriging is shown in Fig. 2b. The lake shows an elliptical morphology with an almost flat lake bottom. The distance between adjacent points of the generated grid is $2.93 \mathrm{~m}$ in each axis. This is approximately half the average spacing of the input data. The estimated minimum depth by kriging is $18.16 \mathrm{~m}$, which is very close to the observed depth.
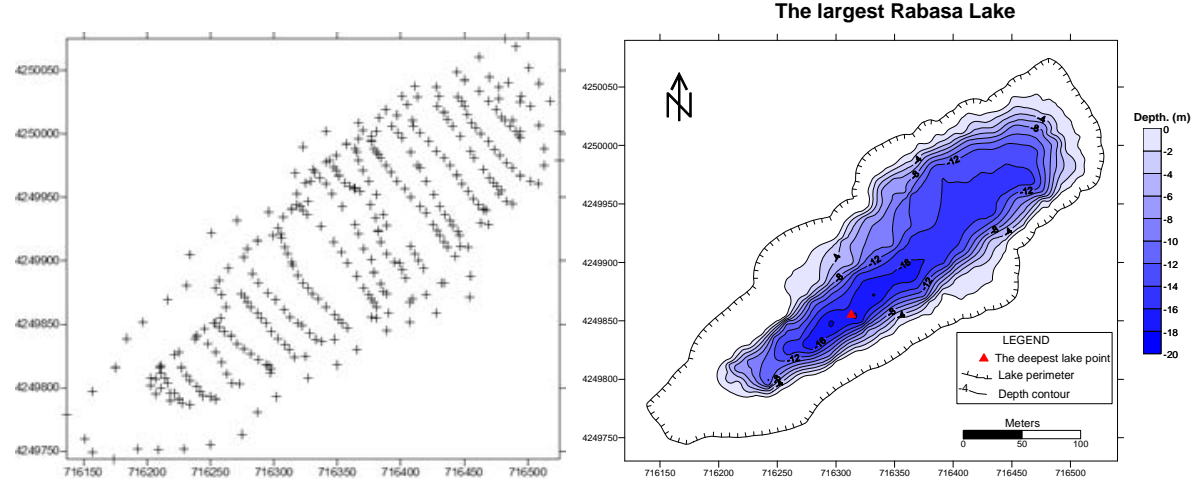

Fig. 2a. Field points measured of the largest Rabasa Lakes. Fig. 2b. Corresponding bathymetric chart (i.e., contour map) obtained by ordinary kriging. Water depth is measured in meters. Coordinate axes are in UTM units.

The knowledge of the morphology of the lake allows us to establish aquifer-lake connections (in case the groundwater level is known) and to compute the storage capacity of the lake. Other statistics, such as the area and volume of the basin at different depths (Fig.3) can be computed. The resulting values are paramount in hydrological studies to characterize and forecast the behaviour of the lake depending on other environmental variables. For example, they can be used in balance equations to predict the response of the water stored in the wetland to several input and output water flows such as rain, springs, runoff, evaporation, water pumping, etc. According to the fourth report of the Intergovernmental Panel on Climate Change [6] forecast, consid- 
ered climate change scenarios suggest a decrease of the water inputs due to fewer precipitations and lower groundwater level, and possible runoff due to isolated rainfalls.
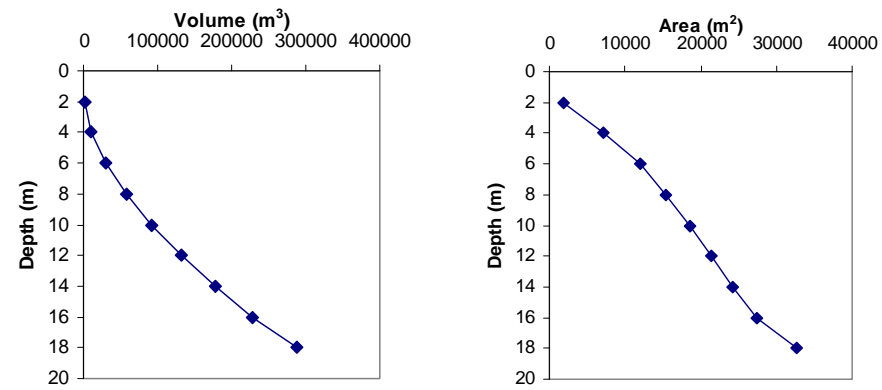

Fig. 3. Depth-volume and depth-area (hypsometric) curves of the largest Rabasa Lakes. Depth is measured from the surface of the lake.

\section{Conclusion}

In this work, a case study of the application of least squares interpolation of scattered 3-D points (kriging) has been presented for a hydrological characterization of a lake. The sonar technology used to acquire the physical measurements to be interpolated was selected based on technical considerations (lake size, accuracy, etc.) as well as economical ones. The proposed methodology is mathematically well founded and reliably describes the bathymetry of the lake bed in agreement with the observations.

Acknowledgments. Authors acknowledge the Regional Government of Alicante and the IGME for the partnership and cofunding related to this project. We thank Prof. A. Valdés (Complutense University of Madrid) for his useful comments.

\section{References}

1. Geng, X. and Zielinski, A.: Precise Multibeam Acoustic Bathymetry. Marine Geodesy, vol. 22(3), pp. 157-167 (1999)

2. Whitman, E.C.: Laser airborne bathymetry - Lifting the littoral Sea Technology, vol. 37(8), pp. 95-98 (1996)

3. SURFER Software, v.8.01 (2002). Scientific Software Group. http://www.ssgsurfer.com/

4. Chiles, J.P. and Delfiner, P.: Geostatistics, Modeling Spatial Uncertainty, Wiley

Series in Probability and statistics. (1999)

5. Tonkin, M.J. and Larson, S.P.: Kriging water levels with a regional-linear and point-logarithmic drift. Ground Water. vol. 40 (2), pp. 185-193 (2002)

6. Pachauri, R.K. and Reisinger, A. (Eds.): Contribution of Working Groups I, II and III to the Fourth Assessment Report of the Intergovernmental Panel on Climate Change. IPCC, Geneva, Switzerland. (2007) 